Marquette University

e-Publications@Marquette

Biomedical Engineering Faculty Research and Publications

Summer 2016

\title{
Attenuation of the Ganglion Cell Layer in a Premature Infant Revealed with Handheld Spectral Domain Optical Coherence Tomography
}

\author{
Mara R. Goldberg \\ Medical College of Wisconsin \\ Fouad R. Zakka \\ Medical College of Wisconsin \\ Joseph Carroll \\ Marquette University \\ Deborah M. Costakos \\ Medical College of Wisconsin
}

Follow this and additional works at: https://epublications.marquette.edu/bioengin_fac

Part of the Biomedical Engineering and Bioengineering Commons

\section{Recommended Citation}

Goldberg, Mara R.; Zakka, Fouad R.; Carroll, Joseph; and Costakos, Deborah M., "Attenuation of the Ganglion Cell Layer in a Premature Infant Revealed with Handheld Spectral Domain Optical Coherence Tomography" (2016). Biomedical Engineering Faculty Research and Publications. 416.

https://epublications.marquette.edu/bioengin_fac/416 


\section{ATTENUATION OF THE GANGLION \\ CELL LAYER IN A PREMATURE \\ INFANT REVEALED WITH HANDHELD \\ SPECTRAL DOMAIN OPTICAL \\ COHERENCE TOMOGRAPHY}

Mara R. Goldberg, BS,* Fouad R. Zakka, MD,* Joseph J. Carroll, PhD, $* \dagger \dagger \S$

Deborah M. Costakos, MD*

Purpose: To report on subclinical retinal abnormalities shown through handheld spectral domain optical coherence tomography on a premature infant.

Methods: Case report.

Results: The initial and follow-up exams on a premature infant revealed severely attenuated ganglion cell and nerve fiber layers. There was cystoid macular edema in both eyes at the initial visits, which resolved by the 1-year follow-up.

Discussion: Optical coherence tomography can reveal significant retinal abnormalities in premature infants which are not detectable through funduscopic exam. Documenting such findings may be useful for the comprehensive management of vision problems in children with a history of premature birth.

RETINAL CASES \& BRIEF REPORTS 10:229-231, 2016

From the *Department of Ophthalmology, Medical College of Wisconsin, Milwaukee, Wisconsin; $\dagger$ Department of Biophysics, Medical College of Wisconsin, Milwaukee, Wisconsin; $\neq$ Department of Biomedical Engineering, Marquette University, Milwaukee, Wisconsin; and \$Department of Cell

Supported by NIH Grant P30EY001931 (J.J.C.). Additional support from the Russel J. and Betty Jane Shaw Fund of the Greater Milwaukee Foundation (J.J.C. and D.M.C.), the VitreoRetinal Surgery Foundation (F.R.Z.), Thomas M. Aaberg, Sr. Retina Research Fund (F.R.Z. and J.J.C.), and an unrestricted departmental grant from Research to Prevent Blindness (J.J.C. and D.M.C.). This investigation was conducted in a facility constructed with support from Research Facilities Improvement Program Grant Number C06 RR016511 from the National Center for Research Resources, National Institutes of Health (J.J.C.).

None of the authors have any financial/conflicting interests to disclose.

Reprint requests: Deborah M. Costakos, MD, Department of Ophthalmology, Medical College of Wisconsin, 925, N. 87th Street, Milwaukee, WI 53226; e-mail: dcostakos@mcw.edu

This is an open access article distributed under the terms of the Creative Commons Attribution-NonCommercial-NoDerivatives License 4.0 (CC BY-NC-ND), which permits downloading and sharing the work provided it is properly cited. The work cannot be changed in any way or used commercially.
Biology, Neurobiology, and Anatomy, Medical College of Wisconsin, Milwaukee, Wisconsin.

Retinopathy of Prematurity (ROP) is a disease that Rcauses abnormal blood vessel growth and the formation of scar tissue in premature infants. Color fundus imaging has been used to document these changes resulting from ROP. ${ }^{1}$ More recently, handheld spectral domain optical coherence tomography (SD-OCT) has been shown to provide valuable information in this challenging clinical population by multiple groups. Spectral domain optical coherence tomography has been used to identify cystoid macular edema and to quantify retinal development in premature neonates. ${ }^{2-5}$ The handheld probe allows for noncontact imaging and 3-dimensional imaging of the retina demonstrating findings that have not been seen in 2-dimensional photography. This may allow for more comprehensive and quantifiable screenings for ROP and other retinal disorders that affect this critical population. ${ }^{2-4}$ We report a case in which the Bioptigen handheld SD-OCT was being used during routine screening for ROP and cystoid 
Fig. 1. Attenuation of ganglion cell and nerve fiber layers observed with SD-OCT. A. SD-OCT B-scan from a male infant who presented with an abnormal nerve fiber layer (NFL) and ganglion cell layer (GCL), with macular edema resulting in altered foveal pit morphology. B. SD-OCT B-scan from a patient with normal retinal layers for this stage of development. Despite cystic changes in the inner nuclear layer, clear delineation of the inner retinal layers is visible. SD-OCT shows that the photoreceptor layers are beginning to be seen at the nasal edge of each image, indicating likely normal outer retinal development. The longitudinal reflectivity profile (LRP) analysis further demonstrates a disruption of the NFL and GCL, though the inner plexiform
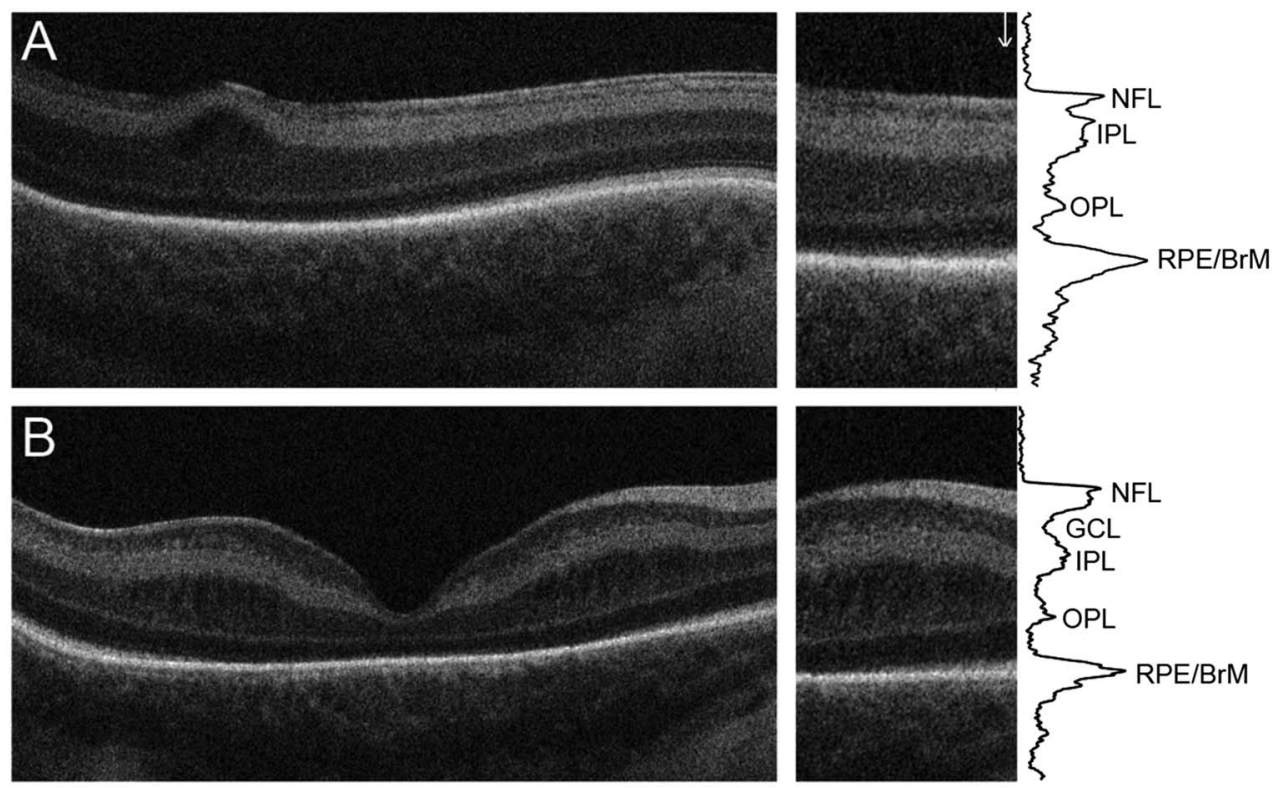

layer (IPL) appears to be of expected thickness. OPL, outer plexiform layer; RPE, retinal pigmented epithelium. Naming of retinal bands follows that of Staurenghi et al. ${ }^{6}$

macular edema, and severe attenuation of the ganglion cell layer and a thin nerve fiber layer was noted.

\section{Case Report}

An African American male was born at 26 weeks gestation with a birth weight of $610 \mathrm{~g}$. The infant had complications of extreme prematurity including prolonged ventilation requirements, pulmonary hemorrhage, heart defects (patent ductus arteriosus, atrial septal defect), bilateral Grade IV intraventricular hemorrhage, periventricular leukomalacia, and presumed seizures. Additionally, the patient had perforated necrotizing enterocolitis requiring peritoneal drainage, anemia of prematurity, and an umbilical hernia.
At the initial ROP screening exam, ROP was graded Stage 0 Zone 2. The optic nerves were formed and were of normal color.

The first SD-OCT images were acquired at the adjusted gestational age of 34 weeks and showed bilateral cystoid macular edema. The results were then compared with scans done on other infants at similar developmental stages using a longitudinal reflectivity profile analysis. The longitudinal reflectivity profile is simply a plot of the reflectivity of the retinal layers in the SD-OCT image as a function of scan depth. This revealed severe attenuation of the ganglion cell layer and a thinned nerve fiber layer in the scans of this infant (Figure 1). Follow-up exams performed 2 and 4 weeks later showed worsening macular edema bilaterally, and a continued absence of the ganglion cell layer and apparent

Fig. 2. Persistent disruption of ganglion cell and nerve fiber layers observed with SD-OCT. A. SD-OCT B-scan acquired from the male patient at the 1-year follow-up exam. B. SDOCT B-scan from a 1-year-old patient with normal retinal lamination. The longitudinal reflectivity profile (LRP) analysis demonstrates normal outer retina and foveal pit development, while the ganglion cell layer (GCL) and nerve fiber layer (NFL) remain severely attenuated. EZ, ellipsoid zone; IPL, inner plexiform layer; IZ, interdigitation zone; OPL, outer plexiform layer; RPE, retinal pigmented epithelium.
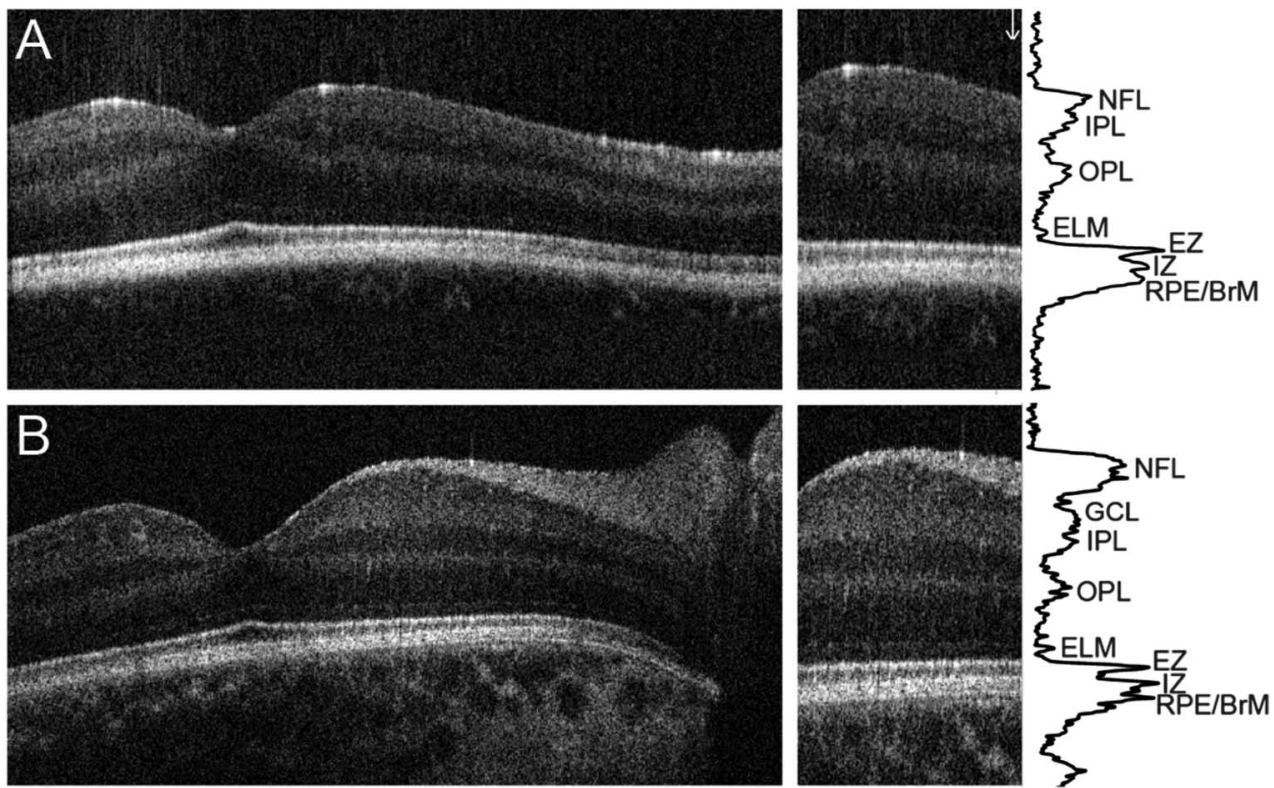
degradation of the nerve fiber layer. However, the patient's retinas vascularized without complication.

One year later the child came in for a follow-up exam. He was noted to have global delays. His external, slit lamp and fundus exams appeared normal. Vision was central, steady and maintained in both eyes. There was no nystagmus and pupils were reactive and ocular alignment was orthotropic. The retina was flat and optic nerves, macula, and vessels appeared normal. Refraction measured +1.5 sphere in the right eye and +2.0 sphere in the left eye. Spectral domain optical coherence tomography done during the visit revealed a more developed outer retina, a normal appearing foveal pit with complete excavation of the inner retinal layers, and a significant reduction in the cystoid macular edema (Figure 2A). However, comparison to an SD-OCT with a child at the same age (Figure 2B) demonstrates a clear absence of a ganglion cell layer and a thin nerve fiber layer.

\section{Discussion}

Cystoid macular edema is a seemingly common entity among approximately $50 \%$ of infants undergoing screening for ROP. ${ }^{3-5}$ However, the marked thinning of the nerve fiber layer and absence of a visible ganglion cell layer has not previously been described in a live infant to our knowledge. Ganglion cell loss has been reported in anencephalic fetuses by 14 weeks gestation and is thought to result from cortical agenesis causing a retrograde degeneration of the lateral geniculate nucleus and subsequently the retinal ganglion cells. Interestingly, the early loss of ganglion cells did not affect subsequent retinal development. ${ }^{7}$ Our patient did not have a neural tube defect, however.

Using SD-OCT, nerve fiber layer loss and ganglion cell layer loss have been reported in adults with ocular pathology including ocular neuropathies in which peripheral field loss is correlated with thinning of the nerve fiber layer. ${ }^{8}$ But even in eyes that have end stage optic neuropathy with no light perception, retinal nerve fiber layer thickness does not fall below $30 \mu \mathrm{m} .{ }^{9}$ It is unclear whether the ganglion cell layer was present prenatally and subsequently lost or if it simply failed to develop at all in our patient.

During the third month of gestation, at the inner neuroblastic layer, ganglion cells migrate inward and form a separate layer from Mueller cells. If there was some teratogenic disruption at this time or absence of chemical signaling within this layer, development may have been arrested in this process. The outer neuroblastic layer continues development well beyond this time frame suggesting that an insult at this time may not stop further differentiation of the other layers of the retina. ${ }^{7,10}$
It is unclear if and how the lack of the ganglion cell layer will affect visual function, but at this time the patient has not developed clinical signs of poor vision. Visual fields will not be able to be assessed until the child is considerably older. Also it is unclear as to whether the thin nerve fiber layer will functionally mimic an optic neuropathy or put this child at earlier or greater risk of vision loss if glaucoma or optic neuropathy were to subsequently develop.

As SD-OCT imaging of infants becomes more widespread, it will be important to document similar unusual findings to begin to define what is possibly artifact, and the range of pathology in this population at risk of poor vision related to the many complications of prematurity.

Key words: ganglion cell layer, retinopathy of prematurity, optical coherence tomography, retinal development.

\section{References}

1. Wallace DK, Freedman SF, Zhao Z. Evolution of plus disease in retinopathy of prematurity: quantification by ROPtool. Trans Am Ophthalmol Soc 2009;107:47-52.

2. Chavala SH, Farsiu S, Maldonado R, et al. Insights into advanced retinopathy of prematurity using handheld spectral domain optical coherence tomography imaging. Ophthalmology 2009;116:2448-2456.

3. Maldonado RS, O'Connell R, Ascher SB, et al. Spectraldomain optical coherence tomographic assessment of severity of cystoid macular edema in retinopathy of prematurity. Arch Ophthalmol 2012;130:569-578.

4. Dubis AM, Subramaniam CD, Godara P, et al. Subclinical macular findings in infants screened for retinopathy of prematurity with spectral domain-optical coherence tomography. Ophthalmology 2013;120:1665-1671.

5. Dubis AM, Costakos DM, Subramamian CD, et al. Subclinical macular findings in infants screened for retinopathy of prematurity with spectral-domain optical coherence tomography. Arch Ophthalmol 2012;130:1291-1300.

6. Staurenghi G, Sadda S, Chakravarthy U, Spaide RF. Proposed lexicon for anatomic landmarks in normal posterior segment spectral-domain optical coherence tomography: the IN - OCT Consensus. Ophthalmology 2014;1-6.

7. Hendrickson A, Djajadi H, Erickson A, Possin D. Development of the human retina in the absence of ganglion cells. Exp Eye Res 2006;83:920-931.

8. Kim KE, Park KH, Yoo BW, et al. Topographic localization of macular retinal ganglion cell loss associated with localized peripapillary retinal nerve fiber layer defect. Invest Ophthalmol Vis Sci 2014;55:3501-3508.

9. Chan CK, Miller NR. Peripapillary nerve fiber layer thickness measured by optical coherence tomography in patients with no light perception from longstanding nonglaucomatous optic neuropathies. J Neuroophthalmol 2007;27:176-179.

10. Hartnett ME. Pediatric Retina. Philadelphia, PA: Lippencott Williams \& Wilkins,2005;1-6. 